OPEN ACCESS

International Journal of

Environmental Research and

Public Health

ISSN 1660-4601

www.mdpi.com/journal/ijerph

Article

\title{
Risk Assessment of Heavy Metals in Surface Sediments from the Yanghe River, China
}

\section{Jing Li}

Key Laboratory of Ecosystem Network Observation and Modeling, Institute of Geographic Sciences and Natural Resources Research, Chinese Academy of Sciences, Beijing 100101, China; E-Mail: jingli@igsnrr.ac.cn; Tel./Fax:+86-10-64-889-300

External Editor: Paul B. Tchounwou

Received: 6 October 2014; in revised form: 20 November 2014 / Accepted: 21 November 2014 / Published: 28 November 2014

\begin{abstract}
The magnitude and ecological relevance of metal pollution from the upstream of water sources after emergency pollution events was investigated by applying a set of complementary sediment quality assessment methods: (1) geochemical assessment based on background value (the geoaccumulation index); (2) comparisons with sediment quality guidelines (SQGs); (3) an evaluation of the combined pollution according to the risk index (RI); and (4) investigation of the chemical patterns of target heavy metals $(\mathrm{Cd}, \mathrm{Zn}, \mathrm{Cr}, \mathrm{Pb}$, Ni). The geoaccumulation indices $\left(I_{g e o}\right)$ suggested that the magnitude of heavy metal pollution of the sediment of Yanghe River decreased in the order of $\mathrm{Cd}>\mathrm{Zn}>\mathrm{Pb}>\mathrm{Cr}>\mathrm{Ni}$. Risk analysis also suggested that $\mathrm{Cd}$ and $\mathrm{Zn}$ concentrations were sufficiently elevated as to cause adverse biological effects in this study area. According to the RI values, $27 \%$ of total sampling sites showed considerable ecological risk for the water body, and 53\% of total sampling sites showed very high ecological risk for the waterbody. Sediment-bound Cd was found to be predominantly associated with the exchangeable phase of the sediment (25\%-68\%), while $\mathrm{Cr}, \mathrm{Ni}, \mathrm{Zn}$ and $\mathrm{Pb}$ showed the strongest association with the residual fractions $(60 \%-92 \%, 53 \%-67 \%, 24 \%-85 \%$ and $35 \%-67 \%$, respectively).
\end{abstract}

Keywords: emergency pollution event; Index of geoaccumulation; community bureau of reference (BCR); sediment quality guidelines; risk index 


\section{Introduction}

In the past few decades, heavy metals accumulation in the environment has been attracting increasing attention from both researchers and policymakers because of their toxicity, persistence in the environment and subsequent accumulation in aquatic habitats [1-5]. Sediments play a major role in determining the pollution patterns of aquatic systems. They act as both carriers and sinks for contaminants, reflecting the history of pollution, and providing a record of catchment inputs into aquatic ecosystems [6-9].

The Guanting Reservoir is situated in the northwest part of Beijing [10]. Historically, Guanting Reservoir has been used as one of the two sources of water for agriculture, industry, and municipalities in Beijing [11,12]. Since the 1970s, the Yanghe River, upstream of Guanting Reservoir, has undergone significant agricultural and industrial development and consequently water in Guanting Reservoir has become contaminated. Two well-known pollution events took place in 1972 and 1989. In 2009, the third pollution event happened along the Yanghe River, and the total damaged farmlands were approximately 12-18 $\mathrm{km}^{2}[13,14]$. Because of this, since 1997, the Guanting Reservoir is no longer been used as a source of drinking water for Beijing. Recently, the government has been reconsidering using the Guanting Reservoir for drinking water supply, because of severe water shortages in Beijing. However, another emergency pollution event along the Yanghe River took place in 2009, causing fish in the aquatic ecosystem to die while residents who drank the water became sick. Our sampling plan and investigation was carried out shortly after the emergency pollution event. The data provided in this study is considered to be very important for reservoir remediation, especially since the Guanting Reservoir will serve as one of the main drinking water sources for Beijing in the foreseeable future.

On the basis of earlier researches [15-18], a comprehensive and reliable scheme of the preliminary risk assessment of metal contamination in surface sediments should contain: (1) comparisons with background values; (2) an evaluation of combined pollution; (3) comparisons of concentrations with the values of sediment quality guidelines; and (4) an investigation on partitioning the carrier operationally defined phases of metals.

The sediment quality guidelines (SQGs) have been used to identify "contaminants of concern" in aquatic ecosystems and to rank "areas of concern" on a regional or national basis, and have also been used in numerous other applications, including the design of monitoring programs, interpreting historical data, conducting remedial investigations and ecological risk assessments and so on $[19,20]$. SQGs are very important for protection of benthic organisms in freshwater ecosystems and can be used to assess sediment ecosystem health [7]. Many different SQGs have been developed [19,21]. We chose to adopt two levels of sediment quality guidelines in this study: the TEL and PEL. These two assessment values, delineated three ranges of chemical concentrations that were rarely (minimal effect range; concentrations equal to and below the TEL), occasionally (possible effect range; concentrations above the TEL, but below the PEL), and frequently (probable effect range; concentrations equal to and above the PEL) associated with adverse biological effects [22].

All of mentioned approaches focus on ecological risk assessment of a single metal. However, naturally occurring heavy metal pollution is in the form of combined pollution. The potential ecological risk index developed by Hakanson is based on the assumption that the sensitivity of the aquatic system depends on its productivity. This methodology was a very useful and comprehensive 
methodology which can be used to evaluate the combined pollution risk of an aquatic system through a toxic-response factor for a given substance [23].

Due to chemical and geological conditions, heavy metals in sediments can exist in different forms: soluble, exchangeable, bound to organic matter, occluded in $\mathrm{Mn}$ and/or Fe oxides, as a component of carbonates, phosphates, sulphurs, or other secondary minerals, or bound to silicates (residual) [9]. Thus, the carrier operationally defined phases analysis of heavy metals might provide much useful information regarding the chemical nature or potential mobility and bioavailability of a particular element, which consequently can offer a more realistic estimate of actual environmental impact [24].

The objectives of the research paper were to: (1) determine concentrations of the metals cadmium $(\mathrm{Cd})$, nickel $(\mathrm{Ni})$, lead $(\mathrm{Pb})$, chromium $(\mathrm{Cr})$ and zinc $(\mathrm{Zn})$ in surface sediments of the Yanghe River; (2) to investigate the environmental risk associated with the metal contents of sediments using available SQGs; (3) to assess the combined pollution of target metals in different sampling sites; and (4) to determine the chemical carrier operationally defined phases of heavy metal $(\mathrm{Cd}, \mathrm{Cr}, \mathrm{Pb}, \mathrm{Ni}$ and $\mathrm{Zn}$ ) in sediment from the Yanghe River in order to evaluate their relative mobility and bioavailability.

\section{Materials and Methods}

\subsection{Study Area}

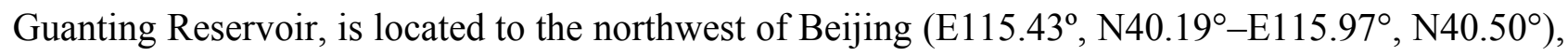
which includes $98 \mathrm{~km}^{2}$ of water and $820 \mathrm{~km}^{2}$ of land. Our study area was the $106 \mathrm{~km}$ long Yanghe River, upstream of Guanting Reservoir, with a total catchment area of $9762 \mathrm{~km}^{2}$. Weather in the area is a cool temperature continental monsoon climate, with an average annual temperature between $3{ }^{\circ} \mathrm{C}$ and $9{ }^{\circ} \mathrm{C}$ and a mean annual precipitation between 370 and $480 \mathrm{~mm}$. The annual accumulated temperature greater than $10{ }^{\circ} \mathrm{C}$ ranges from 2100 to $3600{ }^{\circ} \mathrm{C}$. Land use in the region includes farms, orchards, fallow lands and lots of industrial land. There were more than 300 industrial and mining enterprises, producing about $7.8 \times 10^{7} \mathrm{t}$ of wastewater annually. Most of this waste water was discharged into the river and reservoir without any treatment.

\subsection{Sediment Sampling}

In August of 2009, 15 sediment samples were collected along the upstream of water source. The sampling sites were located using a global positioning system. The distribution of the sampling points is shown in Figure 1. At each sampling point, approximately the top $5 \mathrm{~cm}$ of sediments were collected using a self-made sediment cores sampler. All samples were sealed in clean polyethylene bags and put in a cooled box on site. The cooled samples were brought back to the lab to be freeze-dried until required.

\subsection{Metal Analysis}

The samples were freeze dried and then ground to a small enough size to pass through a 200-mesh sieve and digested with a mixture of concentrated $\mathrm{HCl}-\mathrm{HNO}_{3}-\mathrm{HF}-\mathrm{HClO}_{4}$ [25]. About $0.25 \mathrm{~g}$ of sediment was subjected to a digestion solution, and the mixture then was heated on an electric heating plate at $200{ }^{\circ} \mathrm{C}$. After being perchloric acid smoked, the mixture was heated for another 3 min then 
cooled to room temperature. After cooling, the residue was digested again with the digestion solution at $200{ }^{\circ} \mathrm{C}$ to dryness. The detection limits were $0.02 \mathrm{mg} / \mathrm{kg}$ for $\mathrm{Cd}, 0.2 \mathrm{mg} / \mathrm{kg}$ for $\mathrm{Cr}, 1 \mathrm{mg} / \mathrm{kg}$ for Ni, $\mathrm{Pb}$ and $\mathrm{Zn}$. Samples were carefully handled to avoid introduction or loss of trace elements during preparation and analysis. All materials used during analytical determinations were kept in Teflon or other metal-free containers.

Figure 1. Sampling sites along the Yanghe River.

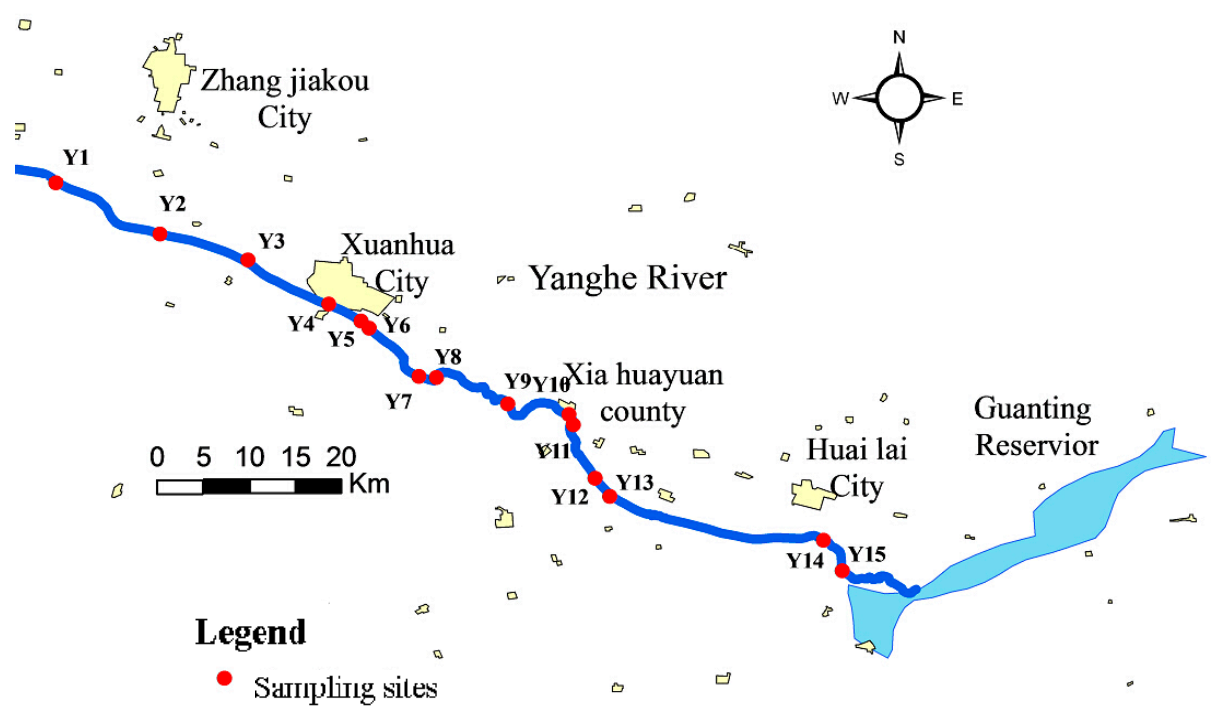

Chemical carrier operationally defined phases of traces in the sediment samples was performed based on the Bureau of Reference (BCR) sequential extraction procedure (SEP) [26,27]. The standard reference material (BCR 701) was used to verify the accuracy of the sequential extraction method. The recovery rates for heavy metals ranged from $86 \%$ (for $\mathrm{Zn}$ in the exchangeable phase) to $116 \%$ (for $\mathrm{Cr}$ in the residual fraction). This gave partitioning in four chemical phases: (1) exchangeable; (2) Fe/Mn oxides; (3) organic matter/sulfides; (4) residual fraction. All supernatants were decanted into acid washed polyethylene containers and refrigerated prior to analysis. Between each phase of the SEP, samples were washed using $10 \mathrm{~mL}$ Milli-Q water. The extraction was performed for $0.5 \mathrm{~g}$ of dried sediment samples in $50 \mathrm{~mL}$ polypropylene centrifuge tubes. The detailed procedure used in this experiment is given in Table 1 .

Table 1. Sequential extraction scheme for heavy metal fractionation in sediments.

\begin{tabular}{lll}
\hline Step & Phases & Procedure \\
\hline 1 & Exchangeable fraction & $0.11 \mathrm{M}$ ammonium acetate, $20 \mathrm{~mL}$, room temperature, shake for $16 \mathrm{~h}$ \\
2 & Fe/Mn oxides & $0.5 \mathrm{M}$ hydroxylammonium chloride $(\mathrm{pH} 2), 20 \mathrm{~mL}$, room temperature, shake \\
& & for $16 \mathrm{~h}$ \\
& & $8.8 \mathrm{M}$ hydrogen peroxide $(\mathrm{pH}$ of $2-3), 5 \mathrm{~mL}$, room temperature, $1 \mathrm{~h}$, \\
& Organic & followed $85^{\circ} \mathrm{C}, 1 \mathrm{~h}$, occasionally shake; add $5 \mathrm{~mL} 8.8 \mathrm{M}$ hydrogen peroxide \\
3 & matter/sulfides & (pH of $2-3$ ), $85^{\circ} \mathrm{C}, 1 \mathrm{~h}$; add $1 \mathrm{M}$ ammonium acetate $(\mathrm{pH}=2), 25 \mathrm{~mL}$, \\
& & room temperature, shake for $16 \mathrm{~h}$
\end{tabular}


Concentrations of the metals $\mathrm{Cd}, \mathrm{Ni}, \mathrm{Pb}, \mathrm{Cr}$ and $\mathrm{Zn}$ in the digestion solution were determined by ICP-MS. Quality control was assured by the analysis of duplicate samples and standard reference materials. The standard reference materials (GSS-1 were used for total element analysis; percentage recoveries ranged from $94 \%$ (for $\mathrm{Cd}$ ) to $114 \%$ (for $\mathrm{Zn}$ ). In majority of cases the sums of the extracted fractions agree, to within $15 \%$, with the independently determined total metal concentrations discussed above, supporting the overall accuracy of the extraction procedure. Analytical precision, expressed as relative standard deviation, was generally better than $10 \%$.

\subsection{Statistical Analyses}

Statistical analyses were conducted by use of Microsoft Excel and SPSS 13.0 statistical software on a personal computer, and the results included maximum, minimum, mean, skew and Coefficient of Variation (CV). The distribution of concentrations was tested with the Shapiro-Wilk method to determine if they approximated the normal probability distribution.

\section{Results and Discussion}

\subsection{Levels of Heavy Metal}

The descriptive statistics for the concentrations of heavy metals in the sediments of the Yanghe River are presented in Table 2. The Shapiro-Wilk test indicated that the concentrations of all of metals followed normal distributions (S-W $p>0.05$ ). The heavy metal background levels in soils of Hebei Province were used as background values. The mean concentration of $\mathrm{Cd}(3.78 \mathrm{mg} / \mathrm{kg}$, $\mathrm{dw})$ was greater than its background value $(0.19 \mathrm{mg} / \mathrm{kg}, \mathrm{dw})$. All of sediment samples significantly exceeded the background value. The mean concentration of $\mathrm{Zn}$ was $2.40 \times 10^{2} \mathrm{mg} / \mathrm{kg}$, dw, which was significantly greater than the corresponding background value of $73.6 \mathrm{mg} / \mathrm{kg}$, dw. The range of $\mathrm{Zn}(905 \mathrm{mg} / \mathrm{kg}, \mathrm{dw})$ between the minimum and maximum values, was greatest of the elements studied and had a coefficient of variation of $119 \%$ and skew of 1.72 which were also the greatest of the elements studied. This observation is the result of the heterogeneity of concentrations of $\mathrm{Zn}$ with a few locations having greater concentrations. The number of samples significantly exceeding the reference value for $\mathrm{Cr}, \mathrm{Pb}$ and $\mathrm{Ni}$ were 9,8 and 3, respectively.

Table 2. Heavy metal concentrations in Yanghe River sediments (mg/kg).

\begin{tabular}{|c|c|c|c|c|c|}
\hline Index & $\mathrm{Cr}$ & Cd & Zn & $\mathbf{P b}$ & $\mathbf{N i}$ \\
\hline Max & 111 & 8.66 & 942 & 59.3 & 36.8 \\
\hline Min & 40.7 & 0.64 & 37.1 & ND & 10.8 \\
\hline Mean & 74.7 & 3.78 & 238 & 23.1 & 20.5 \\
\hline Coefficient of variation $\%$ & 32.5 & 54.6 & 119 & 66.6 & 36.8 \\
\hline Skew & 0.09 & 0.80 & 1.72 & 0.57 & 0.84 \\
\hline $\mathrm{S}-\mathrm{W} p$ & 0.34 & 0.63 & 0.09 & 0.63 & 0.23 \\
\hline Background value of Hebei soil ${ }^{\text {a }}$ & 63.8 & 0.19 & 73.6 & 22.4 & 25.4 \\
\hline Number exceeding reference values ${ }^{\mathbf{b}}$ & 9 & 15 & 9 & 8 & 3 \\
\hline
\end{tabular}

Notes: ND, not detectable; ${ }^{\mathbf{a}}: \mathrm{Xu}$, et al. [28]; ${ }^{\mathbf{b}}$ : The number whose value is significantly greater than the corresponding reference value. 
The greatest concentrations of $\mathrm{Cd}, \mathrm{Pb}$ and $\mathrm{Zn}$ occurred at location $\mathrm{Y} 8$, while the greatest concentrations of $\mathrm{Cr}$ and $\mathrm{Ni}$ were found at sites Y12 and Y1, respectively. Coal-related industries, such as iron and steel plants, power stations and coal yards, have developed significantly along the bank of Yanghe River. For example, the Xuanhua iron and steel plant that was established 80 years ago, is located upstream of Y8 [14]. Due to the smelting of iron and steel plants, metals including Cd, $\mathrm{Pb}$ and $\mathrm{Zn}$ could be discharged into river [29,30]. Zheng et al. [31] studied the metal contamination in the sediments of rivers in Huludao City, and found that the Huludao Zinc Plant was the main reason for the metal pollution in the river. There were also lots of coal yards located nearby the site Y8 [28]. Coal which contains high metals concentrations could be transported to the river by rainfall. In addition, higher $\mathrm{Cd}$ and $\mathrm{Ni}$ concentration might be ascribed to the effluents of variety of industrial plants scattered along the river bank (leather factory, flour mill, oil refining plants).

The geoaccumulation index $\left(I_{\text {geo }}\right)$ was also used to assess metal pollution in sediments of Yanghe River. The geoaccumulation index is expressed as follows:

$$
I_{\text {geo }}=\log _{2}\left[\frac{C_{n}}{1.5 B_{n}}\right]
$$

where $C_{\mathrm{n}}$ is the measured concentration of the heavy metal (n) in the sediment, $B_{\mathrm{n}}$ is the geochemical background value in the average shale of element $n$, and 1.5 is the background matrix correction factor due to lithogenic effects. The $I_{\text {geo }}$ is associated with a qualitative scale of pollution intensity, seven classes of pollution from unpolluted $\left(I_{\text {geo }} \leq 0\right)$ to extremely polluted $\left(I_{\text {geo }} \geq 5\right)$ are defined for the quality of sediments based on $I_{\text {geo }}$ values [32]. Following this classification the surficial sediments collected along the upstream of Guanting Reservoir can be categorized as strongly polluted with Cd $\left(3<\right.$ mean $\left.I_{\text {geo }}<4\right)$, unpolluted to moderately polluted with $\mathrm{Zn}\left(0<\right.$ mean $\left.I_{\text {geo }}<1\right)$, and unpolluted with $\mathrm{Cr}, \mathrm{Pb}$ and $\mathrm{Ni}$. In conclusion, based on the $I_{\text {geo }}$ classification, the magnitude of heavy metal pollution of the sediment of Yanghe River decreased in the order of $\mathrm{Cd}>\mathrm{Zn}>\mathrm{Pb}>\mathrm{Cr}>\mathrm{Ni}$ (Figure 2).

\subsection{Sediment Quality Guidelines}

The heavy metal concentrations were compared with the TEL and PEL values and the results presented in Table 3. The percentages of samples exceeding the TEL and PEL values for Cd were $100 \%$ and $53 \%$, respectively. Among the investigated elements, Cd most often exceeded the TEL and PEL values. The percentages of samples exceeding the TEL and PEL values for Zn were $40 \%$ and $33 \%$, respectively. The percentages of samples exceeding the TEL value for $\mathrm{Pb}, \mathrm{Ni}$ and $\mathrm{Cr}$ were $13 \%$, $67 \%$ and $93 \%$, respectively. These three trace elements in the sediment samples fell below the PEL value in all sediment samples. However, exceedance of SQG values does not firmly guarantee the occurrence of deleterious ecological effects, unless they are also coherent with regional background levels $[8,33,34]$. Although $93 \%$ and $67 \%$ sediment samples had concentrations of $\mathrm{Cr}$ and $\mathrm{Ni}$ exceeding their respective TEL, which were expected to have adverse biological effects occasionally, however, $60 \%$ and $20 \%$ of sediment samples had the concentration of $\mathrm{Cr}$ and $\mathrm{Ni}$ exceeding their respective regional background levels. Therefore, contamination ranking of $\mathrm{Cr}$ and $\mathrm{Ni}$ load of sediments against the regional background levels seems to be more reliable. This result is agreement with consequences reported in the literature [8]. 
Figure 2. Box-and whisker plots of the index of geoaccumulation of metals in the sediment of Yanghe River.

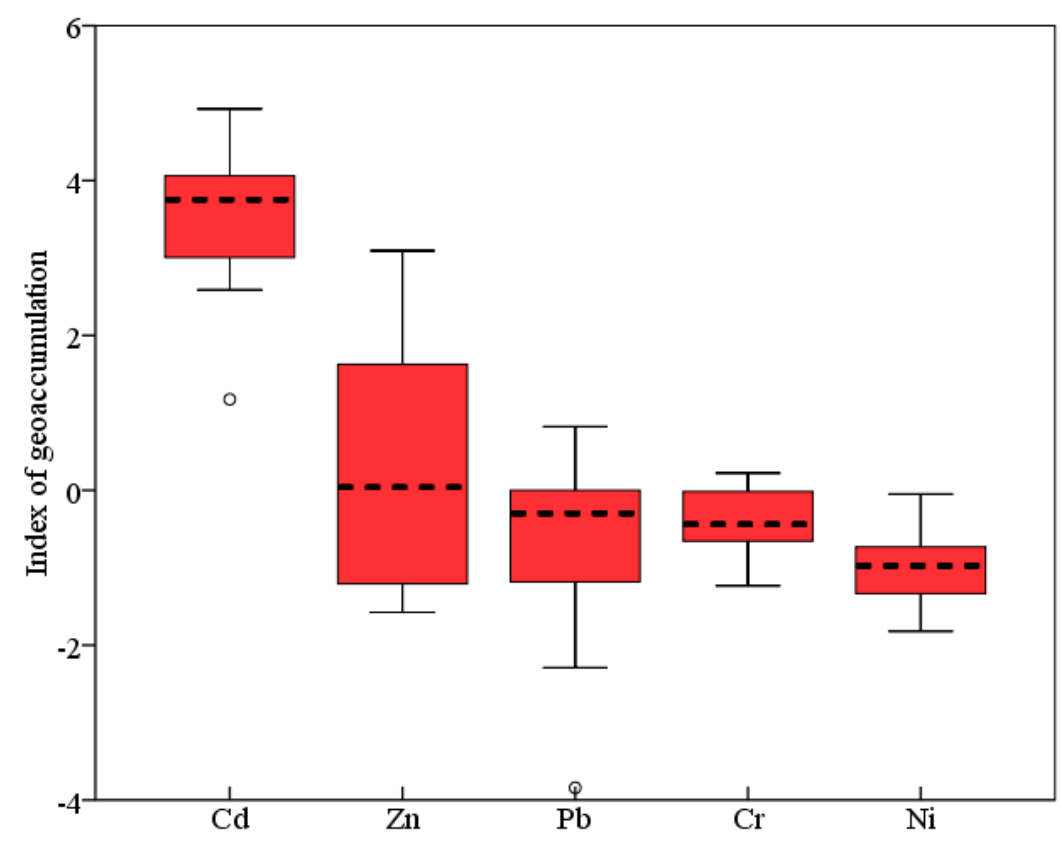

Table 3. Comparison of sediment quality guidelines with average values for the Yanghe River.

\begin{tabular}{lccccc}
\hline \multirow{2}{*}{ Index } & \multicolumn{5}{c}{ Sediment Metal Concentrations (mg/kg) } \\
\cline { 2 - 6 } & $\mathbf{N i}$ & $\mathbf{C r}$ & $\mathbf{P b}$ & $\mathbf{Z n}$ & $\mathbf{C d}$ \\
\hline TEL & 16.0 & 42.0 & 35.0 & 123 & 0.60 \\
PEL & 43.0 & 160 & 91.0 & 315 & 3.50 \\
Average values for the study area & 20.5 & 74.7 & 23.1 & 238 & 3.78 \\
\% samples which exceeded TEL & 67 & 93 & 13 & 40 & 100 \\
\% samples which exceeded PEL & 0 & 0 & 0 & 33 & 53 \\
\hline
\end{tabular}

\subsection{Comparative Ecological Impact Assessment}

To assess the effect of multiple metals pollution in the sediments from the upstream of water source, the quantitative approach developed by Hakanson was used. According to this methodology, the potential ecological risk index (RI) is defined as:

$$
R I=\sum_{i=1}^{n}\left(T_{i} \times \frac{C_{i}}{C_{o}}\right)
$$

where $T_{i}$ is the toxic-response factor for a given substance (e.g., $\mathrm{Cd}=30, \mathrm{~Pb}=\mathrm{Ni}=5, \mathrm{Cr}=2, \mathrm{Zn}=1$ ); $C_{i}$ represents metal content in the sediments; and $C_{o}$ is the regional background value of heavy metals in the sediments. In this study, the heavy metal content of soils in Beijing (Table 2) was used as the regional background value. The RI value is associated with a qualitative scale of pollution intensity, samples may be classified as following: RI $<150$ - low ecological risk for the waterbody; $150<\mathrm{RI}<300$-moderate ecological risk for the waterbody; $300<\mathrm{RI}<600$ - considerable ecological risk for the water body; $\mathrm{RI}>600$ — very high ecological risk for the waterbody. 
The RI of sediment samples from the upstream of Guanting Reservoir are compared in Figure 3. The RI value for the sampling site Y13 was lower than 150, suggesting that this sampling site exhibited low ecological risk from heavy metal pollution. Four sampling sites (Y2, Y3, Y5, and Y6) along the Yanghe River had RI values ranging from 300 to 600, which indicate high considerable risk from heavy metals pollution. RI values of the rest sediment samples (53\% of total sampling sites) were higher than 600, which mean high ecological risk of heavy metals.

Figure 3. Potential ecological risk indices (RI) of heavy metals in surface sediments from the Yanghe River.

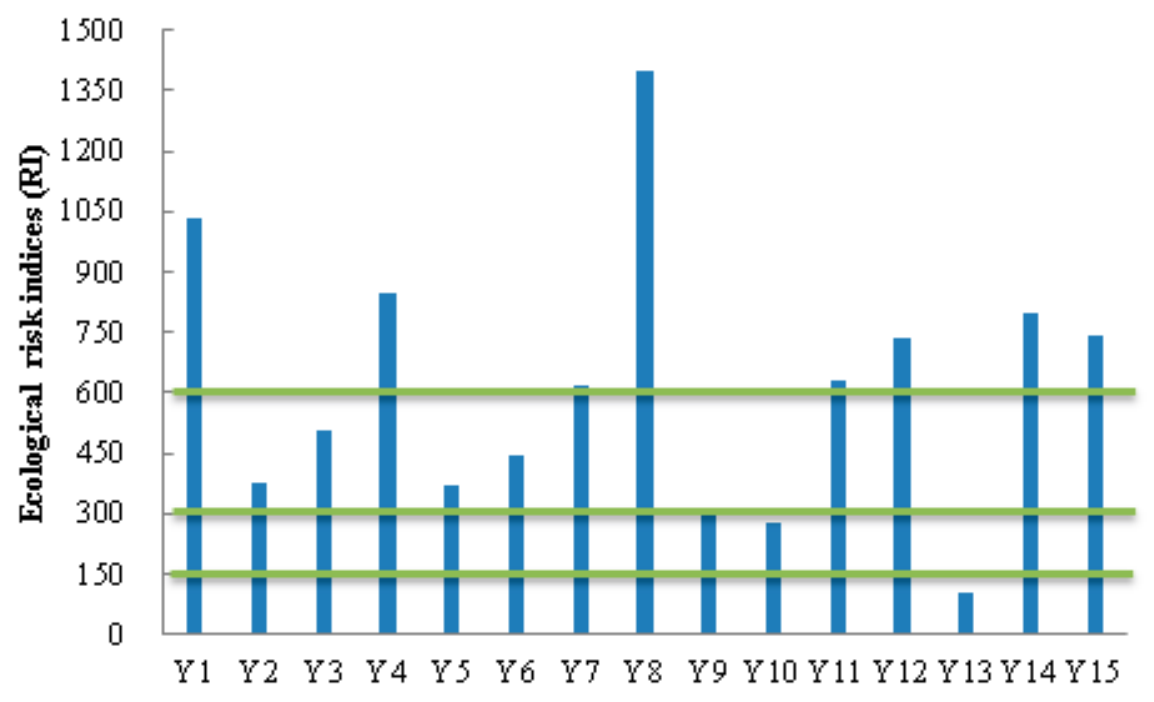

\subsection{The Carrier Operationally Defined Phases of Heavy Metals}

The carrier operationally defined phases distribution of heavy metals in sediments is of importance to investigate the metal mobility and availability. The chemical partitioning of trace metals in the sediment samples among the exchangeable, Fe/Mn oxides, sulfides/organic matter and residual fractions, is plotted in Figure 4. Each geochemical fraction is presented as the percentage of the sum of all fractions.

As Figure 4 shows, we may know that the fractionation patterns of $\mathrm{Cr}$ and $\mathrm{Ni}$ in different sediment samples were somewhat similar. Both of the sediment samples were characterized by a dominance of the residual fraction, $56 \%-92 \%$ for $\mathrm{Cr}$ and $53 \%-67 \%$ for $\mathrm{Ni}$, respectively. The second phase is organic/sulfides with $5.0 \%-29 \%$ for $\mathrm{Cr}$ and $12 \%-25 \%$ for $\mathrm{Ni}$, respectively. Minor contributions were found in the exchangeable phase and $\mathrm{Fe} / \mathrm{Mn}$ oxides. Because the exchangeable phases are entirely negligible pollutants, even though the total concentration of $\mathrm{Cr}$ in the river was rather high (from $40.70 \mathrm{mg} / \mathrm{kg}$ to $111.62 \mathrm{mg} / \mathrm{kg}$ ), we can conclude that $\mathrm{Cr}$ and $\mathrm{Ni}$ in the river are negligible pollutants, and mainly derived from natural processes such as weathering and soil formation. 
Figure 4. Partitioning of heavy metals in the sediments.

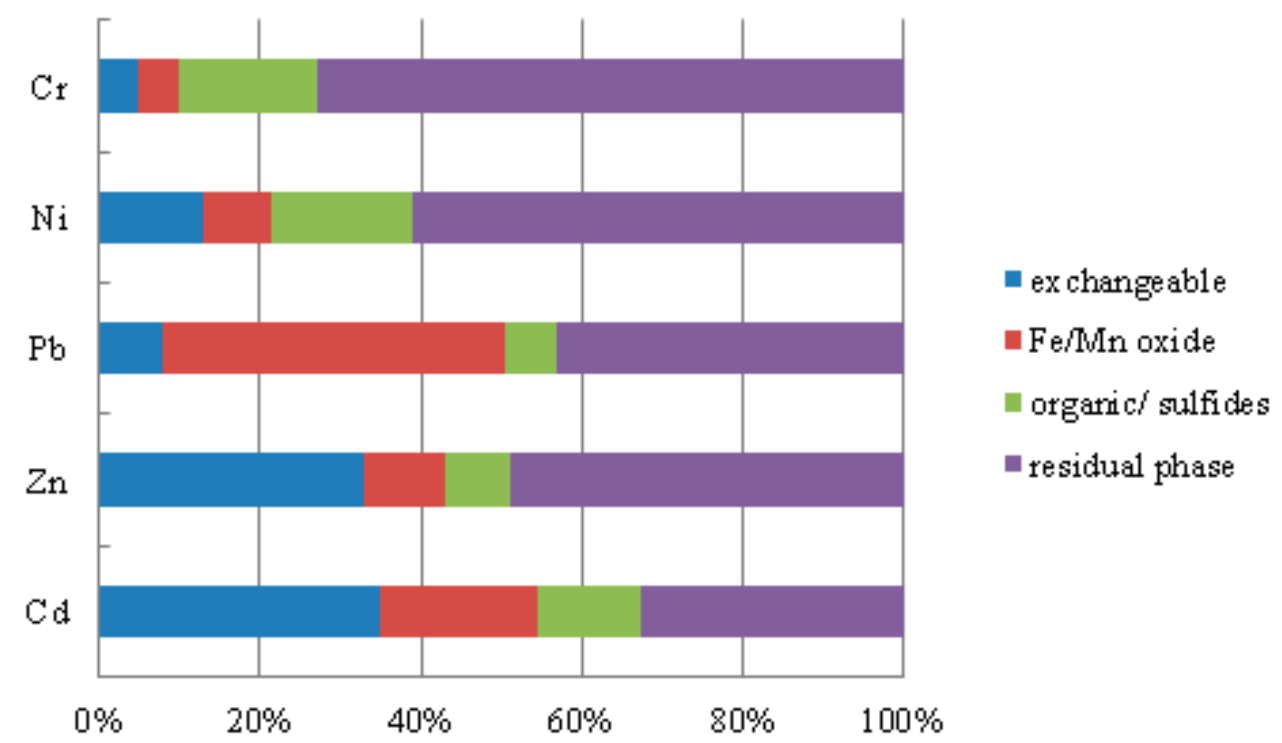

Throughout the river stretch, lead preferentially bound to residual phase (35\%-67\%) and to Fe/ $\mathrm{Mn}$ oxides $(21 \%-56 \%)$, while the exchangeable phase and organic matter/ sulfides accounted for $3 \%-17 \%$ and $3 \%-12 \%$, respectively. Although the average percentage of the exchangeable phase was not high (8\%), with the mean value of total content of $\mathrm{Pb}(23.1 \mathrm{mg} / \mathrm{kg})$, the Fe/Mn oxide phase could be easily released from the sediment phase into the water with changing environmental conditions. As a type of environmental hormone, $\mathrm{Pb}$ can affect the procreation ability of a biological system [24]. Therefore, once $\mathrm{Pb}$ is transferred from the sediment to the water, it poses a higher ecological risk. Therefore, the potentially $\mathrm{Pb}$ pollution in the river should be considered.

$\mathrm{Zn}$ was mainly associated the residual phase $(24 \%-85 \%)$, followed by the exchangeable phase (5\%-62\%), Fe/Mn oxide (4\%-22\%) and organic/ sulfides (4\%-17\%). Among the investigated elements, the variation of $\mathrm{Zn}$ in different fraction of sediment samples is highest of all. High content of $\mathrm{Zn}$ in exchangeable phase and total extractable $\mathrm{Zn}$ in some sediment samples was found to be consistent with the high total concentrations of $\mathrm{Zn}$ in these sampling sites. Taking these two factors into consideration, the potential $\mathrm{Zn}$ pollution in the river should be given more attention.

The operationally defined carrier phases of $\mathrm{Cd}$ were: exchangeable $(35 \%)>$ residual phase $(33 \%)>$ Fe/Mn oxide $(19 \%)>$ organic/ sulfides $(13 \%)$. Low levels of $\mathrm{Cd}$ in the organic/sulfides can be due to the low adsorption constant and labile complex with organic matter [35]. A high content of total extractable Cd was observed in all the sediments (59\%-88\%), with significant amounts of Cd present in the exchangeable phase $(25 \%-68 \%)$. Among the investigated elements, Cd was most strongly present in the exchangeable phase. Cadmium has always been ever considered as a significant metal for environmental behavior. In addition, the total concentration of $\mathrm{Cd}$ in the river was also very high (from 0.64 to $8.66 \mathrm{mg} / \mathrm{kg}$ ). It can be concluded that potential $\mathrm{Cd}$ pollution in the river should be treated seriously.

Based on the analysis of carrier operationally defined phases of metals in the surface sediment along the Yanghe River, the proportion of residual fraction of $\mathrm{Cd}, \mathrm{Pb}$ and $\mathrm{Zn}$ were lower than $\mathrm{Cr}$ and $\mathrm{Ni}$, which means the proportion of $\mathrm{Cd}, \mathrm{Pb}$ and $\mathrm{Zn}$ come from anthropogenic sources were higher than 
the other two metals [36,37]. Industrial development along the Yanghe River has been quick and intensive. There are lots of companies along the bank of the river, such as iron and steel plants, power stations and oil refining plants and so on [13]. In addition, there were also several highways across this area with heavy traffic flow in the past several years [14], so we thought the wastewater from the plants, the atmospheric deposition from energy production and metallurgical industries and the discharge of pollutants from vehicle exhaust might be the possible anthropogenic sources for metals, especially for $\mathrm{Cd}, \mathrm{Pb}$ and $\mathrm{Zn}[36]$.

\section{Conclusions}

This study investigated the magnitude and ecological relevance of metal pollution from the upstream of Yanghe River after an emergency pollution event by applying a set of complementary sediment quality assessment methods. According to the geoaccumulation index $\left(I_{\text {geo }}\right)$ classification, this area has to be considered as "strongly" polluted with $\mathrm{Cd}$, and "unpolluted to moderately" polluted with $\mathrm{Zn}$. Comparisons with sediment quality guidelines revealed that $\mathrm{Cd}$ and $\mathrm{Zn}$ are considered as two principal traces in samples to frequently cause adverse biological effects. From our combined assessment, we judge most sampling sites to be high ecological risk areas. Investigation of the chemical pattern of elements in sediments from the river indicated that high content of total extractable $\mathrm{Cd}$ and $\mathrm{Pb}$ were observed in all sediments, $\mathrm{Zn}$ was mostly enriched in the residual phase and Fe/Mn oxides, and $\mathrm{Cr}$ and $\mathrm{Ni}$ were primarily present in the residual phase.

The metals of greatest concern in the sediments of the Yanghe River were found to be $\mathrm{Cd}$ and $\mathrm{Zn}$. Almost the whole river was contaminated with either or both types of metal. We estimate that heavy metals pollution was one of major contributors to the emergency pollution event in 2009. In order to be able to again use Guanting Reservoir as one of the main drinking water sources for Beijing, remediation and conservation is required along the Yanghe River as soon as possible. This should include: (a) treatment of domestic and industrial sewage; (b) closure of mine works; (c) reduction in the overall primary industrial activities; and (d) political environmental protection policies and actions.

\section{Acknowledgments}

This study was supported by the National Science Foundation (Grant No. 41201514).

\section{Conflicts of Interest}

The authors declare no conflict of interest.

\section{References}

1. Facchinelli, A.; Sacchi, E.; Mallen, L. Multivariate statistical and gis-based approach to identify heavy metal sources in soils. Environ. Pollut. 2001, 114, 313-324.

2. Loska, K.; Wiechula, D. Application of principal component analysis for the estimation of source of heavy metal contamination in surface sediments from the Rybnik Reservoir. Chemosphere 2003, 51, 723-733. 
3. Sakan, S.M.; Dordevic, D.S.; Manojlovic, D.D.; Predrag, P.S. Assessment of heavy metal pollutants accumulation in the Tisza River sediments. J. Environ. Manage. 2009, 90, 3382-3390.

4. Guan, Y.; Shao, C.F.; Ju, M.T. Heavy metal contamination assessment and partition for industrial and mining gathering areas. Int. J. Environ. Res. Public Health 2014, 11, 7286-7303.

5. Fifi, U.; Winiarski, T.; Emmanuel, E. Assessing the mobility of lead, copper and cadmium in a calcareous soil of Port-au-Prince, Haiti. Int. J. Environ. Res. Public Health 2013, 10, 5830-5843.

6. Singh, K.P.; Mohan, D.; Singh, V.K.; Malik, A. Studies on distribution and fractionation of heavy metals in Gomti River sediments-A tributary of the Ganges, India. J. Hydrol. 2005, 312, 14-27.

7. Cevik, F.; Goksu, M.Z.L.; Derici, O.B.; Findik, O. An assessment of metal pollution in surface sediments of seyhan dam by using enrichment factor, geoaccumulation index and statistical analyses. Environ. Monit. Assess. 2009, 152, 309-317.

8. Farkas, A.; Erratico, C.; Vigano, L. Assessment of the environmental significance of heavy metal pollution in surficial sediments of the River Po. Chemosphere 2007, 68, 761-768.

9. Devesa-Rey, R.; Diaz-Fierros, F.; Barral, M.T. Trace metals in river bed sediments: An assessment of their partitioning and bioavailability by using multivariate exploratory analysis. J. Environ. Manage. 2010, 91, 2471-2477.

10. Zhang, S.Z.; Wang, S.X.; Shan, X.Q. Distribution and speciation of heavy metals in surface sediments from Guanting Reservoir, Beijing. J. Environ. Sci. Health A 2002, 37, 465-478.

11. Zhang, H.; Lu, Y.L.; Dawson, R.W.; Shi, Y.J.; Wang, T.Y. Classification and ordination of DDT and $\mathrm{HCH}$ in soil samples from the Guanting Reservoir, China. Chemosphere 2005, 60, 762-769.

12. Wang, T.Y.; Lu, Y.L.; Shi, Y.J.; Giesy, J.P.; Luo, W. Organochlorine pesticides in soils around Guanting Reservoir, China. Environ. Geochem. Health 2007, 29, 491-501.

13. Luo, W.; Wang, T.Y.; Lu, Y.L.; Giesy, J.P.; Shi, Y.J.; Zheng, Y.M.; Xing, Y.; Wu, G.H. Landscape ecology of the Guanting Reservoir, Beijing, China: Multivariate and geostatistical analyses of metals in soils. Environ. Pollut. 2007, 146, 567-576.

14. Xu, L.; Luo, W.; Lu, Y.; Wang, T.; Chen, C.; Giesy, J.P.; Zhang, Y.; Li, J.; Gosens, J. Status and fuzzy comprehensive assessment of metals and arsenic contamination in farmland soils along the Yanghe River, China. Chem. Ecol. 2011, 27, 415-426.

15. Zhang, W.G.; Feng, H.; Chang, J.N.; Qu, J.G.; Xie, H.X.; Yu, L.Z. Heavy metal contamination in surface sediments of yangtze river intertidal zone: An assessment from different indexes. Environ. Pollut. 2009, 157, 1533-1543.

16. Liu, J.L.; Li, Y.L.; Zhang, B.; Cao, J.L.; Cao, Z.G.; Domagalski, J. Ecological risk of heavy metals in sediments of the luan river source water. Ecotoxicology 2009, 18, 748-758.

17. Clozel, B.; Ruban, V.; Durand, C.; Conil, P. Origin and mobility of heavy metals in contaminated sediments from retention and infiltration ponds. Appl. Geochem. 2006, 21, 1781-1798.

18. Pagnanelli, F.; Moscardini, E.; Giuliano, V.; Toro, L. Sequential extraction of heavy metals in river sediments of an abandoned pyrite mining area: Pollution detection and affinity series. Environ. Pollut. 2004, 132, 189-201.

19. MacDonald, D.D.; Ingersoll, C.G.; Berger, T.A. Development and evaluation of consensus-based sediment quality guidelines for freshwater ecosystems. Arch. Environ. Contam. Toxicol. 2000, 39, 20-31. 
20. Long, E.R.; Field, L.J.; MacDonald, D.D. Predicting toxicity in marine sediments with numerical sediment quality guidelines. Environ. Toxicol. Chem. 1998, 17, 714-727.

21. Ankley, G.T.; DiToro, D.M.; Hansen, D.J.; Berry, W.J. Technical basis and proposal for deriving sediment quality criteria for metals. Environ. Toxicol. Chem. 1996, 15, 2056-2066.

22. Smith, S.L.; MacDonald, D.D.; Keenleyside, K.A.; Ingersoll, C.G.; Field, L.J. A preliminary evaluation of sediment quality assessment values for freshwater ecosystems. J. Great Lakes Res. 1996, 22, 624-638.

23. Hakanson, L. An ecological risk index for aquatic pollution-control-A sedimentological approach. Water Res. 1980, 14, 975-1001.

24. Yang, Z.F.; Wang, Y.; Shen, Z.Y.; Niu, J.F.; Tang, Z.W. Distribution and speciation of heavy metals in sediments from the mainstream, tributaries, and lakes of the Yangtze River catchment of Wuhan, China. J. Hazard. Mater. 2009, 166, 1186-1194.

25. National Environmental Bureau (NEB). Water and Waste Analysis, 3rd ed.; Chinese Environmental Science Publish House: Beijing, China, 1998.

26. Rauret, G.; Lopez-Sanchez, J.F.; Sahuquillo, A.; Barahona, E.; Lachica, M.; Ure, A.M.; Davidson, C.M.; Gomez, A.; Luck, D.; Bacon, J.; et al. Application of a modified BCR sequential extraction (three-step) procedure for the determination of extractable trace metal contents in a sewage sludge amended soil reference material (CRM 483), complemented by a three-year stability study of acetic acid and EDTA extractable metal content. J. Environ. Monit. 2000, 2, $228-233$.

27. Yu, R.L.; Hu, G.R.; Wang, L.J. Speciation and ecological risk of heavy metals in intertidal sediments of Quanzhou Bay, China. Environ. Monit. Assess. 2010, 163, 241-252.

28. Xu, L.; Wang, T.Y.; Luo, W.; Ni, K.; Liu, S.J.; Wang, L.; Li, Q.S.; Lu, Y.L. Factors influencing the contents of metals and arsenic in soils around the watershed of Guanting Reservoir, China. J. Environ. Sci. 2013, 25, 561-568.

29. Wang, H.Y.; Stuanes, A.O. Heavy metal pollution in air-water-soil-plant system of Zhuzhou City, Hunan Province, China. Water Air Soil Pollut. 2003, 147, 79-107.

30. Dauvalter, V. Impact of mining and refining on the distribution and accumulation of nickel and other heavy metals in sediments of subarctic lake Kuetsjarvi, Murmansk Region, Russia. J. Environ. Monit. 2003, 5, 210-215.

31. Zheng, N.; Wang, Q.C.; Liang, Z.Z.; Zheng, D.M. Characterization of heavy metal concentrations in the sediments of three freshwater rivers in Huludao City, Northeast China. Environ. Pollut. 2008, 154, 135-142.

32. Müller, G. Schwermetalle in den sedimenten des rheins-Veraenderungen seit 1971. Umschau 1979, 79, 778-783. (In German)

33. Chapman, P.M.; Mann, G.S. Sediment quality values (SQVS) and ecological risk assessment (ERA). Mar. Pollut. Bull. 1999, 38, 339-344.

34. Roach, A.C. Assessment of metals in sediments from lake Macquarie, New South Wales, Australia, using normalisation models and sediment quality guidelines. Mar. Environ. Res. 2005, $59,453-472$. 
35. Baron, J.; Legret, M.; Astruc, M. Study of interactions between heavy-metals and sewage sludges-Determination of stability-constants and complexation capacities of complexes formed with $\mathrm{Cu}$ and Cd. Environ. Technol. 1990, 11, 151-162.

36. Xu, L.; Wang, T.; Ni, K.; Liu, S.; Wang, P.; Xie, S.; Meng, J.; Zheng, X.; Lu, Y. Metals contamination along the watershed and estuarine areas of southern Bohai Sea, China. Mar. Pollut. Bull. 2013, 74, 453-463.

37. Liu, G.; Tao, L.; Liu, X.; Hou, J.; Wang, A.; Li, R. Heavy metal speciation and pollution of agricultural soils along Jishui River in non-ferrous metal mine area in Jiangxi Province, China. J. Geochem. Explor. 2013, 132, 156-163.

(C) 2014 by the authors; licensee MDPI, Basel, Switzerland. This article is an open access article distributed under the terms and conditions of the Creative Commons Attribution license (http://creativecommons.org/licenses/by/4.0/). 